\title{
Glutathione depletion in fibroblasts is the basis for apoptosis-induction by endogenous reactive oxygen species
}

\author{
Birgit Zucker ${ }^{1}$, Jörg Hanusch ${ }^{1}$ and Georg Bauer ${ }^{1,2}$ \\ ${ }^{1}$ Abteilung Virologie, Institut für Medizinische Mikrobiologie und Hygiene, \\ Universität Freiburg, D 79104 Freiburg, Germany \\ 2 corresponding author: Georg Bauer, Abteilung Virologie, Hermann-Herder Str. \\ 11, D-79104 Freiburg, Germany. tel: 0761-203-6595; fax: 0761-203-6562; \\ e-mail:TGFB@sun1.ukl.uni-freiburg.de
}

Received 28.10.96; revised 14.2.97; accepted 4.3.97

Edited by R.A. Knight

\begin{abstract}
Our study aimed at clarifying the role of the intracellular concentration of reduced glutathione for induction of apoptosis in fibroblasts. Treatment of fibroblasts with buthionine sulfoximine (BSO) caused efficient depletion of intracellular reduced glutathione which was followed by substantial cell death. Based on the induction of membrane blebbing, chromatin condensation and DNA strand breaks, cell death was characterized as apoptosis. Apoptosis after glutathione depletion seemed to be induced by endogenous reactive oxygen species (ROS), as it was antagonized by the antioxidant catechol and the hydroxyl radical scavenger DMSO. Paracrine interaction between cells prevented ROSinduced apoptosis and therefore points to the existence of extracellular survival factors. Our data show that the apoptosis-inducing potential of endogenous ROS is controlled by the intracellular glutathione concentration and by paracrine survival factors.
\end{abstract}

Keywords: apoptosis; BSO; glutathione, fibroblast

Abbreviations: BSO, buthionine sulfoximine; ROS, reactive oxygen species; DMSO, dimethyl sulfoxide; TUNEL, TdTmediated dUTP nick end labelling; TGF- $\beta$, tumor growth factor $\beta$; dUTP, d-uridine triphosphate

\section{Introduction}

Apoptosis represents an active form of cell death that is of central importance for tissue homeostasis, development and remodelling (Kerr et al, 1972). Apoptosis is one of the key events during the immune response, leading to the destruction of self-reactive $T$ and $B$ cell clones and to the positive selection of $B$ cell clones producing high affinity lgG. $T$ cells utilize induction of apoptosis for the killing of their targets. In addition, apoptosis represents an important antiviral mechanism (Vaux et al, 1994). Induction of apoptosis after DNA damage (Lowe et al, 1993) counteracts radiation-induced mutagenesis and carcinogenesis. Recently, induction of apoptosis of transformed cells by their nontransformed neighbouring cells has been described as an hitherto unrecognized potential control step of oncogenesis (Bauer, 1995, 1996).

An overwhelming number of apoptosis-inducing stimuli have been described during the last years in various cell systems. In addition, much information has been accumulated on molecules that interfere with induction of apoptosis. In certain systems, the continuous presence of growth or survival factors is required for the inhibition of apoptosis. Their removal leads to immediate onset of apoptosis (Ishizaki et al, 1995; Raff, 1992; Raff et al, 1993).

There is emerging evidence for a central role of reactive oxygen species during induction of apoptosis (for review see Butke and Sandstrom, 1994; Sarafian and Bredesen, 1994; Briehl and Baker, 1996; Slater et al, 1996). This concept is based on several lines of evidence: (1) there are several reports on direct induction of apoptosis by reactive oxygen species (Lennon et al, 1991; Sato et al, 1995), redox cyclers (Dypbukt et al, 1994) or oxidized macromolecules (Escargueil et al, 1992; Sandstrom et al, 1994); (2) several inducers of apoptosis stimulate production of reactive oxygen species in cells (Torres Roca et al, 1995; Yamauchi et al, 1989; Zamzami et al, 1995; Hennet et al, 1993); (3) several ways of apoptosis induction are blocked by antioxidants and radical scavengers (Matthews et al, 1987; Chang et al, 1992; Hockenberry et al, 1993; Kane et al, 1993; Sandstrom et al, 1993; Wolfe et al, 1994; Lin et al, 1995; Slater et al, 1995; Talley et al, 1995; Schaefer et al, 1995; Langer et al, 1996).

The biochemical level of ROS function during induction of apoptosis may be seen at several central points of cellular regulatory systems. ROS can cause activation of apoptosis-related transcription factors, such as NFkappa B (by inactivating their inhibitory subunit) and leading to activation of apoptosis-relevant genes further on (Lin et al, 1995; Westerndorp et al, 1995). ROS may regulate the activity of cysteine-containing proteases or may influence calcium homeostasis (Briehl and Baker, 1996).

Due to the potency of ROS for apoptosis induction, the cellular redox state, i.e. the balance between ROS production and antioxidant defense mechanisms, is of central importance for prevention and regulation of apoptosis (Briehl and Baker, 1996; Slater et al, 1996). It is widely accepted that ROS generated from mitochondrial electron transport systems (Chance et al, 1979) represent an apoptosis-inducing potential that has to be neutralized by the cellular antioxidant defense system in order to avoid induction of apoptosis (Briehl and Baker, 1996; Slater et al, 

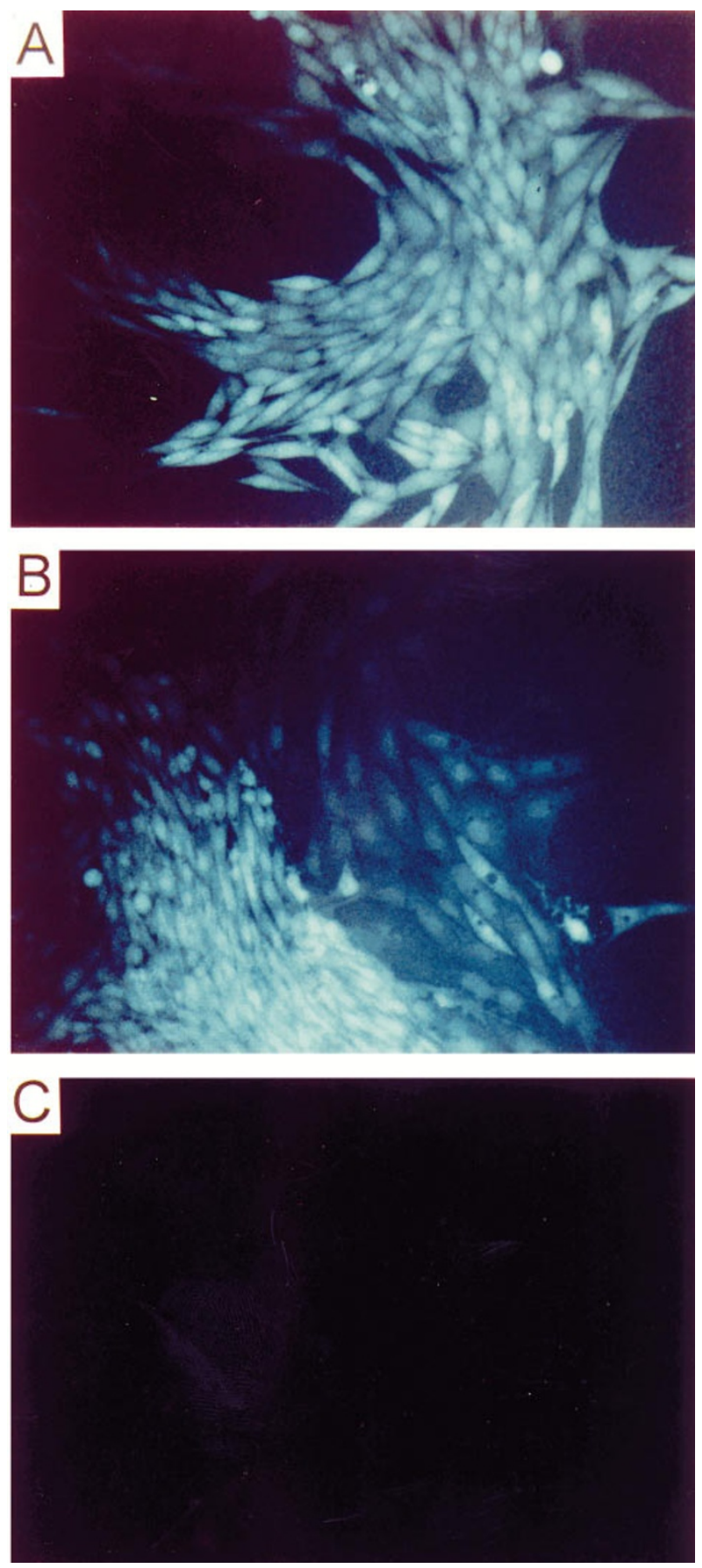

Figure 1 Detection of intracellular glutathione concentration by monochlorobimane staining. A semiconfluent culture of $\mathrm{MxCl} 1$ cells was trypsinized. The cells were pelleted, resuspended and their number was determined. Microscopy ensured that cells were fully dispersed and that there were no aggregates. Cells were seeded sparsely in six well culture clusters to allow growth of 150 individual clones per assay. Medium contained $20 \%$ conditioned medium (i.e. cell-free supernatant from a semiconfluent culture of the same cell type). Conditioned medium allows survival of individual cells at extremely low initial cell density. When the clones had reached a size of 50-100 cells per clone, they remained either untreated $(\mathbf{A}, \mathbf{B})$ or were cultured in the presence of $50 \mu \mathrm{M}$ BSO for $24 \mathrm{~h}$ (C). Clones were then stained with monochlorobimane and the intracellular glutathione content was visualized using a fluorescence microscope. (A) Clone with bright fluorescence; (B) Comparison of a brilliantly stained clone and a clone with distinct, but less brilliant stain; (C) Clone depleted of glutathione by BSO treatment for $24 \mathrm{~h}$.
1996). The glutathione system represents a central and potent antioxidant system with the ability of regulation and regeneration (Meister and Anderson, 1983). It is not unexpected, therefore, that induction of apoptosis by several stimuli leads to glutathione depletion, which in turn enhances the process of apoptosis (Briehl et al, 1995; Slater et al, 1996).

Lowering the glutathione level of cells seems to sensitize them for apoptosis-inducing stimuli (Sato et al, 1995; Fernandes and Cotter, 1994). In a recent review, Slater et al (1996) conclude that experimental lowering of the glutathione content of cells is not sufficient by itself to induce apoptosis. However, they present one striking exception: when the biosynthesis of glutathione in neuronal cells is blocked by buthionine sulfoximine (BSO), the cells go into apoptosis (Ratan et al, 1994). In similar experiments performed by Kane et al (1993), necrotic lesions, rather than apoptosis, seemed to predominate. As the cellular redox state determines the mode of cellular death induced (Dypbukt et al, 1994; Fernandes and Cotter, 1994), the discrepancy between the findings by Kane et al (1993) and Ratan et al (1994) may possibly be due to different glutathione levels maintained during their experiments.

Fibroblasts represent an important model system for the in vitro study of viral and chemical carcinogenesis, oncogene and tumor suppressor gene function, as well as basic intracellular control mechanisms (Bauer, 1996). There is recent experimental evidence for potent nonimmunological cellular mechanisms that selectively kill transformed cells by induction of apoptosis (Jürgensmeier et al, 1994; Schaefer et al, 1995; Bauer, 1996). The use of antioxidants allowed the elucidation of a double function of ROS in this intercellular control system: they seem to be involved in a TGF- $\beta$-triggered signal chain in normal cells and to be required during induction of apoptosis of transformed cells (Langer et al, 1996). For a further understanding of apoptosis-induction in fibroblasts, it is necessary to understand the role of the redox state and of ROS for induction of apoptosis in this particular cell system. Here we show that reduction of intracellular glutathione concentration after BSO treatment leads to specific induction of apoptosis, mediated by endogenous ROS.

\section{Results}

$\mathrm{MxCl} 1$ cells were sparsely seeded and allowed to grow to individual clones (150 clones per assay). When they had reached a size of 50-100 cells per clone, they either remained untreated or received varying concentrations of BSO. The intracellular concentration of reduced glutathione and the degree of cell death were monitored kinetically in parallel assays. After staining with monochlorobimane for detection of reduced glutathione, untreated clonal populations of cells consisted of a majority of brilliantly stained clones and a smaller proportion of clones with a distinct, but less brilliant fluorescent stain (Figures 1 and 2). After $24 \mathrm{~h}$ of BSO treatment, the intracellular concentration of reduced glutathione was below the level of detectability in the vast majority of clones (Figures 1 and 2). Untreated control clones 
did not show a significant degree of cell death during the experiment, whereas in BSO-treated clones glutathione depletion was followed by marked death of a substantial number of individual cell clones (Figure 2). This finding indicates (i) that glutathione depletion was the basis for the cell death observed and (ii) that cells were protected from cell death as long as they showed detectable levels of glutathione.

Dying cells showed membrane blebbing, indicating that apoptosis rather than necrosis had been induced. To ensure that cell death was indeed due to apoptosis, chromatin condensation and integrity of DNA were tested in BSO-treated cell clones and controls. As can be seen in Figure 3A, untreated intact cells showed uncondensed chromatin. After BSO treatment, a substantial number of cells exhibited condensed chromatin (Figure 3B-D). Condensed chromatin corresponded directly to a positive TUNEL reaction, a marker for free $3^{\prime}$ ends of DNA, a typical sign of apoptosis (Figure 3E, F).

The measurement of chromatin condensation allowed a precise determination of the kinetics of induction of apoptosis in a random population of cells after treatment with increasing concentrations of BSO. Therefore, transformed $\mathrm{MxCl} 1$ cells (Figure 4A) or nontransformed $\mathrm{C} 3 \mathrm{H}$ 10T1/2 cells (Figure 4B) were seeded at different densities

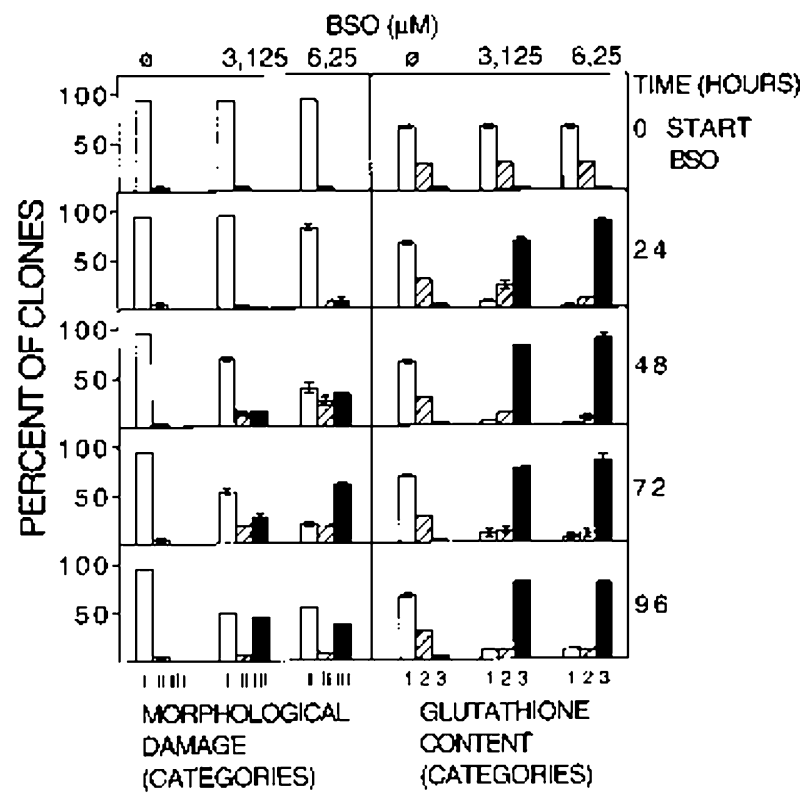

Figure 2 Reduction of glutathione content is followed by cell death. $\mathrm{MxCl} 1$ cells were grown to clones (six well tissue culture clusters, $50-100$ cells per clone, 150 clones per well) and the indicated concentration of BSO was added. At the indicated times, the clonal variation of intracellular glutathione content and the degree of morphological damage of the cells was determined. To determine the glutathione content, assays were stained with monochlorobimane and the clones of the respective assay were categorized in three distinct categories (I=bright stain; II=distinct, but less brilliant stain; III=no stain, indicating complete depletion of glutathione). Morphological damage was determined in unstained cultures, using an inverted microscope and phase contrast. Clones were categorized as follows: I=less than $10 \%$ of dead cells per clone; $I I=10-50 \%$ dead cells per clone; III=more than $50 \%$ dead cells per clone. As indicated in the text, dead cells showed the morphological features of apoptosis. and were treated with increasing concentrations of BSO. Apoptosis was monitored by determination of the percentage of nuclei showing condensed chromatin. As can be seen in Figure $4 A$ and $B$, untreated cells remained intact throughout the experiment and did not show condensed nuclei. In contrast, BSO-treated cells (both transformed and nontransformed) showed chromatin condensation dependent on time and concentration of BSO applied. At higher cell concentration chromatin condensation occurred later and to a lesser degree than at lower cell concentration. This finding indicates a cellular inhibitory effect against apoptosis induction after BSO treatment. Chromatin condensation after BSO treatment was seen both in transformed and nontransformed cells. However, in transformed cells, apoptosis induction (visualized by chromatin condensation) was faster than in nontransformed cells and required less BSO. This result indicates that apoptosis induction after BSO treatment does not differentiate between transformed and nontransformed cells per se. However, transformed cells seems to be more sensitive and to react faster.

To distinguish between a hypothetical direct apoptosis induction by the chemical BSO itself, and ROS-dependent apoptosis inducation after glutathione depletion caused by BSO treatment, transformed and nontransformed cells were treated with increasing concentrations of BSO in the presence of the antioxidant catechol or the hydroxyl radical scavenger DMSO. As can be seen in Table 1, catechol and DMSO caused a significant reduction of apoptosis after BSO treatment, thus pointing to the triggering role of reactive oxygen species in this process.

Our experiments showed a low intraassay variation, but a significant interassay variability of sensitivity to the action of BSO. One of the possible reasons for this effect was seen in some potential selfprotecting effect of the cells used in the experiments. To clarify this point, cells were clonally grown. Then, medium was completely renewed and BSO was added or not. As can be seen in Table 2, addition of BSO directly after removal of old medium caused the most dramatic induction of apoptosis. When BSO was added after $24 \mathrm{~h}$ or later, the induction of apoptosis was drastically reduced. This result suggested the production of protective substances by the cells. This finding was directly confirmed by addition of BSO to cell clones immediately after removal of medium, but in the presence of an excess of normal cells in a tissue culture insert. Under these conditions, due to the protective effect of the cells in the insert, the strong effect of BSO was again significantly reduced.

\section{Discussion}

Untreated cells with detectable intracellular reduced glutathione are protected from spontaneous induction of apoptosis. In contrast, depletion of intracellular reduced glutathione (verified by the absence of detectable fluorescence stain after monochlorobimane staining) was followed, with a lag phase of $24 \mathrm{~h}$ or more, by cell death. This finding demonstrates that cell death is the consequence of glutathione depletion. When BSO was removed immediately after the glutathione content had been lowered maximally, the 

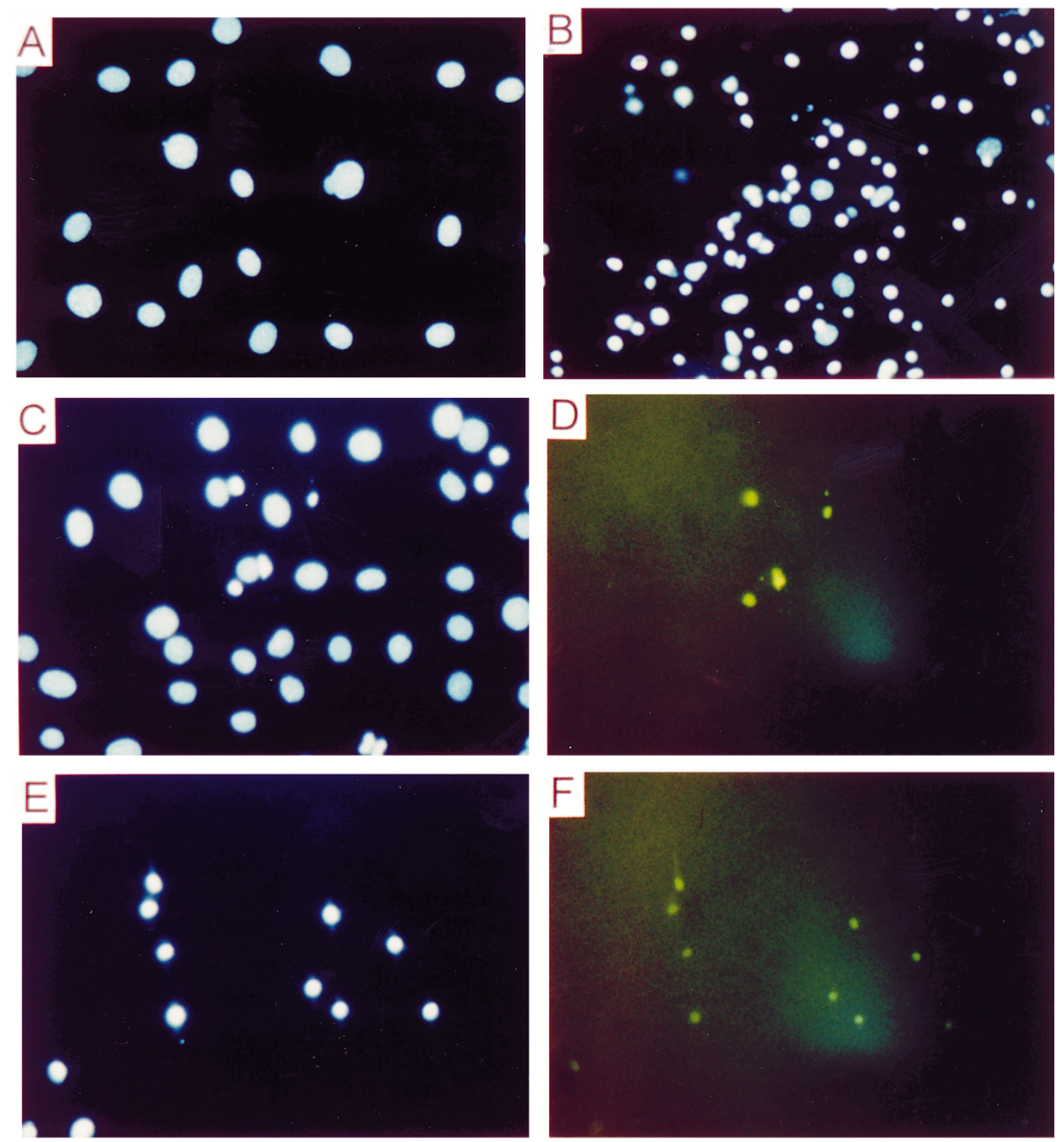

Figure 3 Cell death following glutathione depletion is apoptosis. $4000 \mathrm{MxCl} 1$ cells or $\mathrm{C} 3 \mathrm{H} 10 \mathrm{~T} 1 / 2$ cells were seeded in Costar 96 well tissue culture clusters. Cells remained free of BSO or received $50 \mu \mathrm{M} \mathrm{BSO}$ (MxCl1 cells) or $200 \mu \mathrm{M} \mathrm{BSO}$ (C3H cells). After $24 \mathrm{~h}$ cells were either stained with bisbenzimidine to test for chromatin condensation (A, B, C, E) and in the TUNEL reaction, to test for DNA strand breaks (D,F). (A) untreated MxCl1 cells. (B) BSO-treated MxCl1 cells. (C,E) BSO-treated $\mathrm{C} 3 \mathrm{H}$ cells (bisbenzimidine). (D,F) BSO-treated $\mathrm{C} 3 \mathrm{H}$ cells (TUNEL). Note that the bisbenzimidine staining and TUNEL reaction have been performed in parallel $(\mathbf{C}-\mathbf{F})$, such that exactly the same cells can be compared stained by the two methods.

glutathione content of cells was restored and the degree of cell death was much lower (data not shown). This finding strengthens the conclusion that the low glutathione content is the basis for initiation of cell death. It also shows that the cell death-inducing principle is not fast acting, but requires time, pointing to (i) either the necessity for accumulation of positive triggering events or (ii) the inactivation of a negative regulator of apoptosis.

ROS-induced cell death in glutathione depleted neuronal cells has been characterized either as apoptosis (Ratan et al, 1994) or necrosis (Kane et al, 1993), depending on the cellular system used. Cell death induced in fibroblasts by ROS after glutathione depletion, as studied here, showed stringent criteria characteristic of apoptosis. The appearance of membrane blebbing, chromatin condensation and DNA strand breaks, detectable by the TUNEL reaction, are strong arguments for cell death being due to apoptosis. Double staining both in the TUNEL reaction and for chromatin condensation, as optimized here, allowed us to confirm that both parameters are found in the same cells. Mitotic cells, that show condensed chromatin after staining with bis-benzimidine are easily differentiated from apoptotic cells in the TUNEL reaction. 
A

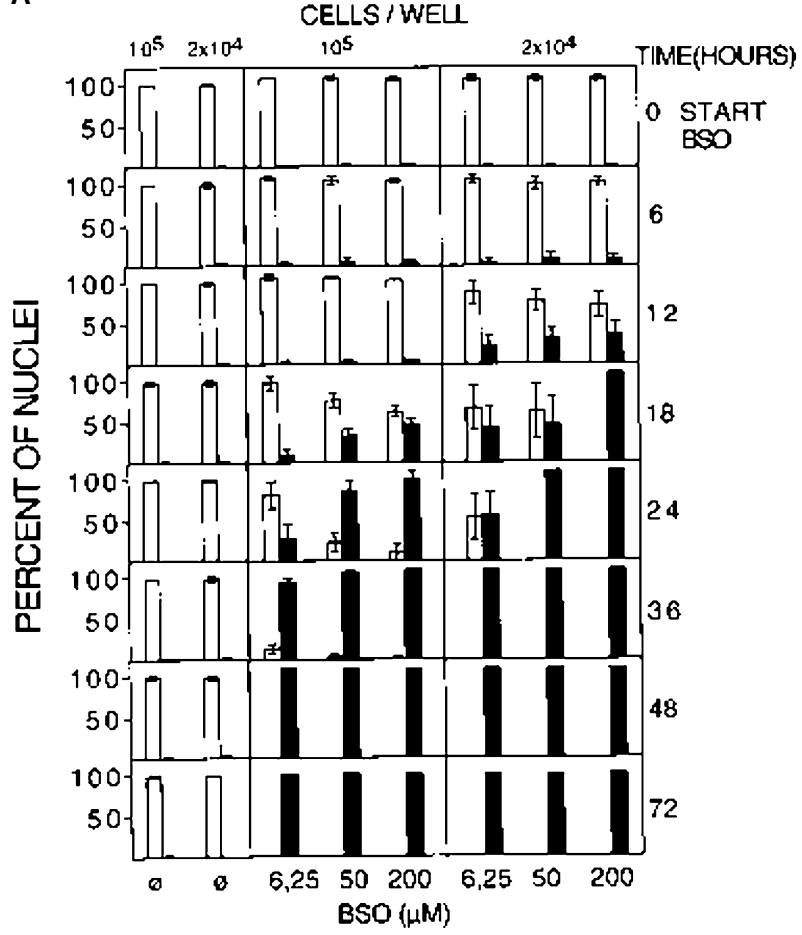

B

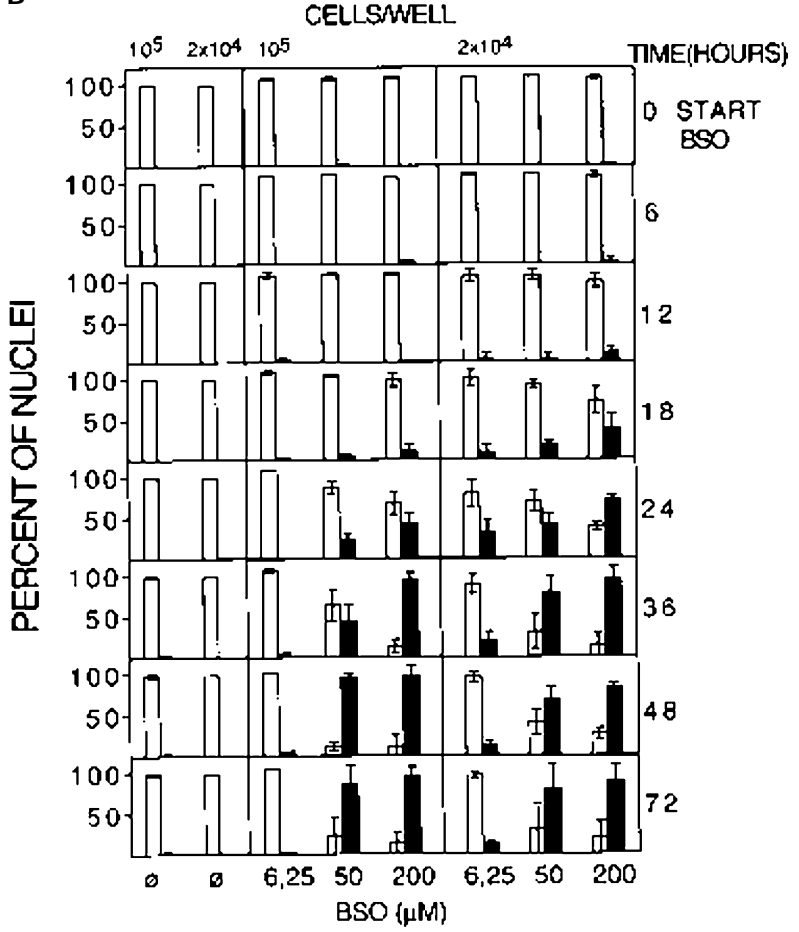

Figure 4 Kinetic analysis of induction of apoptosis in BSO-treated $\mathrm{MxCl} 1$ cells $(\mathbf{A})$ or $\mathrm{C} 3 \mathrm{H} 10 \mathrm{~T} 1 / 2$ cells $(\mathrm{B})$. The indicated numbers of cells were seeded in six well tissue culture clusters. After $24 \mathrm{~h}$, BSO was added the indicated concentrations or not. At the indicated times, parallel assays (duplicates) were stained with bisbenzimidine. The percentages of intact nuclei (open columns) and condensed nuclei (black columns), indicating apoptosis, were determined.
The antioxidant catechol and the hydroxyl radical scavenger DMSO were able to prevent cell death after BSO-directed glutathione depletion. This finding excludes the possibility that cell death is directly induced by BSO and points to the functional role of reactive oxygen species for the induction of apoptosis. Obviously, these ROS species only can play a role after depletion of the intracellular glutathione and seem to be efficiently neutralized under control conditions. These results are novel for fibroblasts and are in line with findings described for neuronal cells (Ratan et al, 1994). Mitochondria might represent a possible source for endogenous reactive oxygen species (Chance et al, 1979).

The exact mechanism of ROS-mediated induction of apoptosis remains enigmatic, so far, as ROS are

Table 1 Induction of apoptosis after glutathione depletion is inhibited by catechol and DMSO

\begin{tabular}{lc}
\hline & $\begin{array}{c}\text { Apoptotic cells } \\
\text { Addition }\end{array}$ \\
\hline (A) C3H $10 \mathrm{~T} 1 / 2$ cells \\
None & $16.5 \pm 4.9$ \\
BSO $(5 \mu \mathrm{M})$ & $75.75 \pm 1.7$ \\
BSO $(5 \mu \mathrm{M})$ plus catechol & $13.5 \pm 5.8$ \\
BSO $(50 \mu \mathrm{M})$ & 100 \\
BSO $(50 \mu \mathrm{M})$ plus catechol & $59 \pm 8.5$ \\
(B) MxC11 cells & 11.4 \\
None & $50.6 \pm 16$ \\
BSO $(5 \mu \mathrm{M})$ & $16.4 \pm 1.3$ \\
BSO $(5 \mu \mathrm{M})$ plus catechol & 100 \\
BSO $(50 \mu \mathrm{M})$ & $47 \pm 6.3$ \\
BSO $(50 \mu \mathrm{M})$ plus catechol & \\
(C) 208 $\mathrm{F} \mathrm{src3}$ cells & $5 \pm 0$ \\
None $(5 \mu \mathrm{M})$ & $35 \pm 3$ \\
BSO $(5 \mu \mathrm{M})$ plus catechol & $16 \pm 6$ \\
BSO $(5 \mu \mathrm{M})$ plus DMSO & $8 \pm 1$ \\
BSO $(5 \mu \mu \mathrm{M})$ & $48 \pm 6$ \\
BSO $(50 \mu)$ plus catechol & $12 \pm 3$ \\
BSO $(50 \mu \mathrm{M})$ & $10 \pm 2$ \\
BSO $(50 \mu \mathrm{M})$ plus DMSO & \\
\hline
\end{tabular}

Cells were seeded in Costar 6 well tissue culture clusters (60 000 cells per assay). After the cells had attached to the plastic, BSO (5 or $50 \mu \mathrm{M}$, as indicated), catechol $(1 \mu \mathrm{g} / \mathrm{ml})$ or DMSO ( $1 \% \mathrm{vol} / \mathrm{vol}$, final concentration) were added. Apoptotic cells were determined after 24-48 $\mathrm{h}$.

Table 2 Production of substances interfering with BSO-mediated apoptosis by cells

\begin{tabular}{lc}
\hline Conditions & $\begin{array}{c}\text { Apoptotic clones } \\
\text { (\%) }\end{array}$ \\
\hline Control & $2.3 \pm 0.2$ \\
BSO (day 0) & $65.7 \pm 10.5$ \\
BSO (day 1) & $20.1 \pm 6.6$ \\
BSO (day 0) plus insert & $14.8 \pm 7.9$ \\
BSO (day 1) plus insert & $12 \pm 2.9$ \\
\hline
\end{tabular}

MxC11 cells were grown to clones of approximately 50 cells per clone (150 clones per assay, Costar 6 well tissue culture clusters). BSO was added at a final concentration of $6.25 \mu \mathrm{M}$ (day 0 ) or after $24 \mathrm{~h}$ (day 1). Controls remained free of BSO. Tissue culture inserts, containing $60000 \mathrm{C} 3 \mathrm{H} 10 \mathrm{~T} 1 / 2$ cells were added to the assays as indicated. The percentage of clones with more than $50 \%$ of apoptotic cells/clone among the total population of clones was determined 4 days after the addition of BSO. Assays were performed in duplicate. 
extremely motile within the cell and are able to interact with thiol-containing proteins (Ziegler, 1985), lipids (Horton and Fairhurst, 1987), or DNA (Halliwell and Aruoma, 1991) leading to activation or inactivation of these molecules. Activation of apoptosis-related transcription factors represents a very intriguing possible mechanism (Westerndorp et al, 1995; Lin et al, 1995). In addition, ROS are known as very effective and specific signal transducers, which may be involved in a variety of biochemical events. Work in progress in our laboratory indicates that the apoptosis-inducing effect of ROS might be due to the inactivation of intracellular survival factors, which negatively regulate the constitutively expressed apoptosis-inducing cellular machinery (Hanusch et al, manuscript in preparation).

Experiments in progress indicate that BSO treatment also causes ROS-mediated apoptosis in fibroblast cell lines derived from p53 null/null mice (data not shown). Therefore, unspecific damage of DNA and subsequent induction of apoptosis by p53 (the guardian of the genome, Lane, 1992) do not seem to be the mechanism underlying the effects presented in this paper.

Induction of apoptosis after glutathione depletion was inversely related to the density of the cells and their culture time before BSO treatment. Presence of tissue culture inserts with high concentrations of cells also drastically inhibited induction of apoptosis after glutathione depletion. These results demonstrate the existence of extracellular transmittable substances that interfere with induction of apoptosis. There are two major possible explanations for this interesting intercellular protection system. The protecting substances in the conditioned medium might represent antioxidants or enzymes involved in oxygen metabolism that interfere with ROS production and/or stability and thus inhibit induction of apoptosis. Alternatively, the substances from the conditioned media might, in the light of a novel fascinating concept (Ishizaki et al, 1995; Raff, 1992; Raff et al, 1993) represent extracellular (paracrine) survival factors that block the apoptosis inducing machinery of cells.

Induction of apoptosis was seen both for transformed cells and their nontransformed parental cells. Induction of apoptosis in this system therefore does not seem to differentiate between transformed and untransformed cells per se. In this respect, it is clearly different from intercellular induction of apoptosis which is strictly dependent on the expression of the transformed phenotype (Beck et al, 1997; Schwieger et al, in preparation; Häufel et al, in preparation). Intercellular induction of apoptosis (induction of apoptosis in transformed cells by neighbouring nontransformed cells) is triggered by TGF- $\beta$ and dependent on ROS at two defined steps (Langer et al, 1996). Nevertheless, induction of apoptosis by endogenous reactive oxygen species after depletion of intracellular reduced glutathione is more efficient and faster in transformed compared to nontransformed cells. This finding may be one of the clues for the evaluation of differences in the control of apoptosis between transformed and nontransformed cells.

\section{Materials and Methods}

\section{Cell lines}

Untransformed mouse $\mathrm{C} 3 \mathrm{H} 10 \mathrm{~T} 1 / 2$ fibroblasts were obtained from $\mathrm{U}$ Rapp, University of Würzburg. The cells do not form colonies in soft agar and exhibit a very low rate of spontaneous transformation.

The transformed mouse fibroblast cell line $\mathrm{MxCl} 1$ has been recently described (Jürgensmeier et al, 1994).

208 Fsrc 3 cells are rat fibroblasts transformed by the viral src oncogene (Iten et al, 1989). They were provided by R Schaefer, Berlin.

\section{Cell culture}

Cells were kept in Eagle's Minimal Essential Medium, containing 5\% fetal calf serum that had been heated for $30 \mathrm{~min}$ at $56^{\circ} \mathrm{C}$ prior to use. Medium was supplemented with penicillin $(40 \mathrm{U} / \mathrm{ml})$, streptomycin $(50 \mu \mathrm{g} / \mathrm{ml}$, neomycin $(10 \mu \mathrm{g} / \mathrm{ml})$, moronal $(10 \mathrm{U} / \mathrm{ml})$ and glutamine $(280 \mu \mathrm{g} / \mathrm{ml})$. Cell culture was performed in plastic tissue culture flasks. Cells were passaged once or twice weekly. For maintenance of plasmid-coded $\mathrm{G} 418$ resistance, cell lines were kept in the presence of $0.5 \mathrm{mg} / \mathrm{ml}$ of $\mathrm{G} 418$.

\section{Determination of the intracellular concentration of reduced glutathione}

Cell clones were stained with $10 \mu \mathrm{M}$ monochlorobimane (Sigma, Deisenhofen, Germany) (Cook et al, 1989). After $15 \mathrm{~min}$, the cells were checked for the intensity of fluorescence at an excitation of $340-$ $380 \mathrm{~nm}$. Control experiments ensured that the staining reaction was at a plateau under the conditions used. Clones were categorized in three categories: brilliant fluorescence, distinct but less brilliant fluorescence and absence of fluorescence (for illustration, please see Figure 1).

Monochlorobimane staining is very specific for reduced glutathione, as it is catalyzed by the enzyme glutathione-S-transferase (Hedley and Chow, 1994). Staining was controlled using monobromobimane, which binds to reduced glutathione nonenzymatically (Hedley and Chow, 1994). Monobromobimane staining showed a higher intensity of fluorescence than staining with monochlorobimane. BSO treatment caused a drastic decrease of fluorescence intensity (both for monochlorobimane and monobromobimane staining), indicating that indeed the reduced glutathione was efficiently depleted. However, the background was higher in BSO-treated cells stained with monobromobimane compared to staining with monochlorobimane.

Untreated rodent fibroblasts showed a certain degree of clonal variability of their intracellular concentration of reduced glutathione, as detected after staining with monochlorobimane and fluorescence microscopy. This clonal heterogeneity is in line with findings of the variability of the intracellular glutathione concentration in vivo (Shrieve et al, 1988). The variability seems to be due to differences in the concentrations of reduced glutathione and cannot be explained by differences in the concentration of glutathione-S-transferase, as staining with monobromobimane led to the same result. The semiquantitative method of fluorescence staining was used in our study to allow monitoring of the intracellular glutathione concentration in situ, especially as a control for the efficiency of BSO treatment. This method was not suitable for exact quantitative determination of the interclonal variability of intracellular glutathione. It was also not in the scope of this study to determine the stability of the interclonal variability after further passage of the cells or to determine the consequences of this variability. 


\section{Reduction of the intracellular concentration of glutathione}

D,L-Buthioninesulfoximine (BSO; Sigma Chemicals, Deisenhofen) was added to growing cells at concentrations between 5 and $200 \mu \mathrm{M}$, as indicated in the respective figure legends. Within 12$24 \mathrm{~h}$, BSO treatment led to the reduction of intracellular reduced glutathione below the level of detectability by monochlorobimane staining. This massive reduction of intracellular glutathione is in accordance with established findings (Hedley and Chow, 1994).

\section{Determination of apoptosis}

Determination of membrane blebbing Membrane blebbing was determined as recently described (Jürgensmeier et al, 1994).

Determination of chromatin condensation Cells were rinsed with PBS and incubated with $1 \mu \mathrm{g} / \mathrm{ml}$ Bis-benzimidine [Hoechst 33258 fluorochrome] $(0.9 \mathrm{mM}$ acetic acid, $1 \mathrm{mM}$ potassium acetate in methanol) for $30 \mathrm{~min}$. After washing with aqua bidest, cells were embedded in Mcllvane/glycerol (Mcllvane's citrate-phosphate buffer: $50 \mathrm{mM}$ potassium dihydrogenphosphate, $50 \mathrm{mM}$ citric acid, $\mathrm{pH}$ 5.5/ glycerol $1: 1)$. Cells were examined with a fluorescence microscope, using excitation at $395-440 \mathrm{~nm}$.

Detection of DNA strand breaks by the TUNEL reaction In some experiments, apoptosis was further assured by the in situ terminal deoxynucleotidyl transferase assay (Gorcyca et al, 1993), which detects DNA strand breaks characteristic for apoptotic cells. A commercially available detection kit (Boehringer, Mannheim, Germany), based on the incorporation of Fluorescein-labelled dUTP, was used.

\section{Acknowledgements}

This work was supported by the Dr Mildred Scheel Stiftung für Krebsforschung (grant W58/94/Ba2) and the Deutsche Forschungsgemeinschaft (grant BA 626/4-1).

\section{References}

Bauer G (1995) Resistance to TGF- $\beta$-induced elimination of transformed cells is required during tumor progression. Int. J. Oncol. 6: 1227-1229

Bauer G (1996) Elimination of transformed cells by normal cells: a novel concept for the control of carcinogenesis. Histol Histopathol. 11: 237-255

Bech E, Schäfer R and Bauer G (1997) Sensitivity of transformed fibroblasts for inter cellular induction of apoptosis is determined by their transformed phenotype. Exp. Cell Res. in press

Briehl MM and Baker AF (1996) Modulation of the antioxidant defence as a factor in apoptosis. Cell Death Differ. 3: 63-70

Briehl MM, Cotgreave IA and Powis P (1995) Downregulation of the antioxidant defence during glucocorticoid-mediated apoptosis. Cell Death Differ. 2: 41 46

Butke TM and Sandstrom PA (1994) Oxidative stress as a mediator of apoptosis. Immunol. Today 15: 7-10

Chance B, Sies H and Boveris A (1979) Hydroperoxide metabolism in mammalian organs. Physiol. Rev. 59: 527-605

Chang DJ, Ringold GM and Heller RA (1992) Cell killing and induction of manganous superoxide dismutase by tumor necrosis factor is mediated by lipoxygenase metabolites of arachidonic acid. Biochem. Biophys. Res. Comm. 188: $538-546$

CookJA, Pass HI, Russo A, lyape Sand Mitchell JB(1989) Use of monochlorobimane for glutathione measurements in hamster and human tumor cell lines. Int. J. Radiat. Oncol. Biol.I. Phys. 16: 1321-1324
Dybukt JM, Ankarcrona M, Burkitt M, Sjöholm A, Ström K, Orenius S and Nicolera $P$ (1994) Different prooxidant levels stimulate growth, trigger apoptosis, or produce necrosis of insulin-secreting RINm5F cells. J. Biol. Chem. 269: 30553-30560

Escargueil I, Nègre-Salvayre A, Pieraggi M-T and Salvayre R (1992) Oxidized low density lipoproteins elicit DNA fragmentation of cultured lymphoblastoid cells. FEBS Lett. 305: 155-159

Fernandes RS and Cotter TG (1994) Apoptosis or necrosis: Intracellular levels of glutathione influence mode of cell death. Biochem. Pharmacol. 48: 675-681

Gorcyca W, Gong J and Darzynkiewicz Z (1993) Detection of DNA strand breaks in individual apoptotic cells by the in-situ terminal deoxynucleotidyl transferase and nick translation assays. Cancer Res. 53: 1945-1951

Halliwell B and Aruoma OI (1991) DNA damage by oxygen-derived species, its mechanism and measurement in mammalian systems. FEBS Lett. 281: 9-19

Hedley DW and Chow S (1994) Evaluation of methods for measuring cellular glutathione content using flow cytometry. Cytometry 15: 349-358

Hennet T, Richter C and Peterhans E (1993) Tumour necrosis factor-alpha induces superoxide anion generation in mitochondria of L929 cells. Biochem. J. 289: $587-592$

Hockenberry DM, Oltvai ZN, Yin X-M, Milliman CL and Korsmeyer SJ (1993) Bcl-2 functions in an antioxidant pathway to prevent apoptosis. Cell 75: 241-251

Horton AA and Fairhurst S (1987) Lipid peroxidation and mechanisms of toxicity. CRC Crit. Rev. Toxicol. 18: 27-79

Ishizaki Y, Cheng L, Mudge AW and Raff MC (1995) Programmed cell death by default in embryonic cells, fibroblasts, and cancer cells. Mol. Biol. of the Cell 6: 1443-1458

Iten E, Ziemiecki A and Schäfer R (1989) The transformation-suppressive function is lost in tumorigenic cells and is restored upon transfer of a suppressor gene. Recent Results Cancer Res. 113: 78-89

Jürgensmeier JM, Viesel E, Höfler P and Bauer G (1994) TGF- $\beta$-treated normal fibroblasts eliminate transformed fibroblasts by induction of apoptosis. Cancer Research 54: 393-398

Kane DJ, Sarafian TA, Anton R, Hahn H, Butler Gralla E, Selverstone Valentine J, Örd Tand Bredesen DE (1993) Bcl-2 inhibition of neural death: decreased generation of reactive oxygen species. Science 262: 1274-1277

Kerr JFR, Wyllie AH and Currie AR (1972) Apoptosis: a basic biological phenomenon with wide-ranging implications in tissue kinetics. Br. J. Cancer 26: $239-257$

Lane DP (1992) p53, the guardian of the genome. Nature 358: 15-16

Langer C, Jürgensmeier JM and Bauer G (1996) Reactive oxygen species act both at TGF- $\beta$-dependent and -independent steps during induction of apoptosis of transformed cells by normal cells. Exp. Cell Res. 222: 117-124

Lennon SV, Martin SJ and Cotter TG (1991) Dose-dependent induction of apoptosis in human tumour cell lines by widely diverging stimuli. Cell Prolif. 24: 203-214

Lin K, Lee S-H, Narayanan R, Baraban JM, Hardwick JM and Ratan RR (1995) Thiol agents and Bcl-2 identify an alphavirus-induced apoptotic pathway that requires activation of the transcription factor NF-kappa B. J. Cell. Biol. 131: $1149-1161$

Lowe SW, Schmitt EM, Smith SW, Osborne BA and Jacks T (1993) p53 is required for radiation-induced apoptosis in mouse thymocytes. Nature 362: 847-849

Matthews N, Neale ML, Jackson SKand Stark JM (1987) Tumour cell killing by tumour necrosis factor: inhibition by anaerobic conditions, free-radical scavengers and inhibitors of arachidonate metabolism. Immunol. 62: 153-155

Meister A and Anderson ME (1983) Glutathione. Ann. Rev. Biochem. 52: 711760

Raff MC (1992) Social controls on cell survival and cell death. Nature 356: 397-400

Raff MC, Barres BA, Burne JF, Coles HS, Ishizaki Y and Jacobson MD (1993) Programmed cell death and control of cell survival: lessons from the nervous system. Science 162: 695-700

Ratan RR, Murphy TM and Baraban JM (1994) Oxidative stress induces apoptosis in embryonic cortical neurons. J. Neurochem. 62: 376-379

Sandstrom PA and Butke TM (1993) Autocrine production of extracellular catalase prevents apoptosis of human CEM T-cell line in serum-free medium. Proc. Natl. Acad. Sci. USA 90: 4708-4712

Sandstrom PA, Tebbey PW, Van Cleave S and Butke TM (1994) Lipid peroxides induce apoptosis in T cells displaying a HIV-associated glutathione peroxidase deficiency. J. Biol. Chem. 269: 798-801

Sarafian TA and Bredesen DE (1994) Invited commentary. Is apoptosis mediated by reactive oxygen species? Free Rad Res. 21:1-8 
Sato N, Iwata S, Nakamura K, Hori T, Mori Kand Yodoi J (1995) Thiol-mediated redox regulation of apoptosis. J. Immunol. 154: 3194-3203

Schaefer D, Jürgensmeier J and Bauer G (1995) Catechol interferes with TGF- $\beta$ induced elimination of transformed cells by normal cells: implications for the survival of transformed cells during carcinogenesis. Int. J. Cancer 60: $520-$ 526

Shrieve DC, Bump EA and Rice GC (1988) Heterogeneity of cellular glutathione among cells derived from a murine fibrosarcoma or a human renal cell carcinoma detected by flow cytometric analysis. J. Biol. Chem. 263: 14107-14114

Slater AFG, Nobel CSI, Maellaro E, Bustamante J, Kimland M and Orrenius S (1995) Nitrone spin traps and a nitroxide antioxidant inhibit a common pathway of thymocyte apoptosis. Biochem. J. 306: 771-778

Slater AFG, Stefan C, Nobel I, van den Dobbelsteen DJ and Orrenius S (1996) Intracellular redox changes during apoptosis. Cell Death Differ. 3: 57-62

Talley AK, Dewhurst S, Perry SW, Dollard SC, Gummuluru S, Fine SM, New D, Epstein LG, Gendelman HE and Gelbard HA (1995) Tumour necrosis factor alpha-induced apoptosis in human neuronal cells: protection by the antioxidant $\mathrm{N}$-acetylcysteine and the genes bcl-2 and crma. Mol. Cell. Biol. 15: 2359-2366

Torres Roca JF, Lecoeur H, Amatore CA and Gougeaon LM (1995) The early intracellular production of a reactive oxygen intermediate mediates apoptosis in dexamethasone-treated thymocytes. Cell Death Differ. 2: 309-319
Vaux DL, Haecker G and Strasser A (1994) An evolutionary perspective on apoptosis. Cell 76: 777-779

Westerndorp MO, Shatrov VA, Schulze-OsthoffK, FrankR, Kraft M, Los M, Krammer PH, Dröge W and Lehmann V (1995) HIV-1 TAt potentiates TNF-induced NF-B activation and cytotoxicity by altering the cellular redox state. EMBO J. 14:546554

Wolfe JT, Ross DR and Cohen GM (1994) A role for metals and free radicals in the induction of apoptosis in thymocytes. FEBS Lett. 352: 58-62

Yamauchi N, Kuriyama H, Watanabe N, Neda H, Maeda M and Niitsu Y (1989) Intracellular hydroxyl radical production induced by recombinant human tumour necrosis factor and its implication in the killing of tumour cells in vitro. Cancer Res. 49: $1671-1675$

Zamzami N, Marchetti P, Castedo M, Decaudin D, Macho A, Hirsch T, Susin SA, Petit PX, Mignotte B and Kroemer G (1995) Sequential reduction of mitochondrial transmembrane potential and generation of reactive oxygen species in early programmed cell death. J. Exp. Med. 182: 367-377

Ziegler DM (1985) Role of reversible oxidation-reduction of enzyme thiols-disulfides in metabolic regulation. Ann. Rev. Biochem. 54: 305-329 